\title{
FAKTOR-FAKTOR YANG MEMPENGARUHI KETERATURAN SIKLUS MENSTRUASI PADA REMAJA PUTRI DI SMA NEGERI 2 SINGARAJA
}

\author{
Luh Yenny Armayanti' ${ }^{1)}$ Putu Ayu Ratna Damayanti ${ }^{1)}$ \\ ${ }^{1}$ Program Studi Sarjana Kebidanan Institut Teknologi dan Kesehatan Bali \\ Jalan Tukad Balian No. 180 Renon Denpasar-Bali \\ E-mail: armayanti61@gmail.com
}

\begin{abstract}
Problems: Menstrual disturbance in adolescense often related with reproductive health problem. Nearly $75 \%$ of adolescents experience menstrual-related disorders such as irregular menstrual cycles. This study aims to analyze the factors that affect the regularity of the menstrual cycle in adolescent girls, including body mass index, hemoglobin levels, physical activity, stress levels, and age of menarche. Research Method: This research is a correlational analytic study with a cross sectional approach. A total of 65 young women became respondents in this study, which were determined using stratified simple random sampling technique. The data collection tools used were questionnaires, weight scales, height gauges and HBmeter. Results: Data were analyzed using descriptive and correlational statistics with a confidence level of $95 \%$. Based on the results of data analysis, it was found that in general the majority of respondents had a normal BMI (50.8\%), 18 years old $(60 \%)$, low $\mathrm{Hb}$ $(52.3 \%)$, light physical activity $(50.8 \%)$, stress levels. moderate $(44.6 \%)$, and the age of menarche was at the age of 13 years $(36.9 \%)$. The results of the correlation analysis showed that the relationship between body mass index, hemoglobin levels, physical activity, stress levels, and age of menarche was respectively $(\mathrm{p}=0.219 ; \mathrm{r}-$ $0.155, \mathrm{p}=0.007 ; \mathrm{r}=-0.330, \mathrm{p}=0.047 ; \mathrm{r}=-0.232, \mathrm{p}=0.005 ; \mathrm{r}=0.334, \mathrm{p}=0.696 ; \mathrm{r}=-0.044)$. Conclusion: There is a relationship between $\mathrm{Hb}$ levels, physical activity and stress levels on menstrual cycle regularity. There is no relationship between BMI and age of menarche with menstrual cycle regularity in adolescent girls.
\end{abstract}

Keywords: physical activity, body mass index, hemoglobin level, menstrual cycle, stress level, age of menarche.

\begin{abstract}
ABSTRAK
Latar Belakang: Gangguan mentruasi pada remaja seringkali berkaitan dengan gangguan kesehatan reproduksi. Hampir $75 \%$ remaja mengalami gangguan menstruasi seperti ketidakteraturan siklus menstruasi. Tujuan: Penelitian ini bertujuan untuk menganalisis faktor-faktor yang mempengaruhi keteraturan siklus menstruasi pada remaja putri diantaranya indeks masa tubuh (IMT), kadar hemoglobin, aktivitas fisik, tingkat stress, dan usia menarche. Metode: Penelitian ini menggunakan desain penelitian analitik korelasional dengan pendekatan potong lintang. Sebanyak 65 orang remaja putri menjadi responden dalam penelitian ini, yang ditentukan dengan menggunakan teknik stratified simple random sampling. Alat pengumpulan data yang digunakan berupa kuesioner, timbangan berat badan, pengukur tinggi badan dan HB meter. Data dianalisis dengan menggunakan statistik deskriptif, dan korelasional dengan tingkat kepercayaan 95\%. Hasil: Berdasarkan hasil analisis data, didapatkan bahwa secara umum mayoritas responden memiliki IMT normal (50,8\%), umur 18 tahun $(60 \%)$, Hb rendah $(52,3 \%)$, aktivitas fisik ringan $(50,8 \%)$, tingkat stress sedang $(44,6 \%)$, dan usia menarche di usia 13 tahun $(36,9 \%)$. Hasil analisis korelasi menunjukkan bahwa hubungan antara indeks masa tubuh, kadar hemoglobin, aktivitas fisik, tingkat stress, dan usia menarche secara berturut-turut adalah ( $p=0,219 ; \mathrm{r}--0,155, \mathrm{p}=0,007 ; \mathrm{r}=-$ 0,330, $\mathrm{p}=0,047 ; \mathrm{r}=-0,232, \mathrm{p}=0,005 ; \mathrm{r}=0,334, \mathrm{p}=0,696 ; \mathrm{r}=-0,044)$. Kesimpulan: Ada hubungan/pengaruh antara kadar $\mathrm{Hb}$, aktivitas fisik dan tingkat stress terhadap keteraturan siklus menstruasi. Tidak ada hubungan/korelasi antara IMT dan usia menarche dengan keteraturan siklus menstruasi pada remaja putri.
\end{abstract}

Kata Kunci: aktivitas fisik, indeks masa tubuh, kadar hemoglobin, siklus menstruasi, tingkat stress, usia menarche. 


\section{PENDAHULUAN}

Masa remaja (adolescence) sering disebut masa transisi atau peralihan dimana terjadi peralihan dari masa anak-anak menuju dewasa yang diikuti dengan adanya perubahan dalam tubuh. Perubahan tersebut neliputi perubahan fisik, psikis dan psikososial (Felicia, Hutagaol, \& Kundre, 2015). Remaja adalah anak yang berusia 10-19 tahun. Menurut World Health Organization (WHO), masa remaja dimulai ketika seorang individu mengalami perubahan dimulai dari saat pertama kali menunjukkan tanda-tanda seksual sekunder hingga mencapai kematangan seksual (Tim Penulis Poltekkes Kemenkes Jakarta, 2010). Secara social ekonomi, pada masa ini terjadi perubahan dari yang tergantung kepada orang tua menuju kondisi mandiri.

Pada masa remaja khususnya remaja perempuan, terjadi proses kematangan sistem reproduksi yang ditandai dengan terjadinya (Parveen \& Siddiqui, 2012). Pada umumnya remaja mengalami menstruasi diuasia 12-13 tahun. Hal ini merupakan proses fisiologi yang mendakan kematangan sistem reproduksi. Menstruasi merupakan proses fisiologis yang dialami oleh setiap wanita remaja dengan rentang usia 12 - 13 tahun. Dimana pada usia ini biasanya telah terjadi kematangan organ reproduksi yang memiliki peranan penting untuk kesejahteraan fisik maupun psikologis.

Menstruasi didefinisikan sebagai perdarahan yang terjadi secara periodik dan terjadu akibat deskuamasi dari lapisan endometrium (Prawirohardjo, 2014). Menstruasi yang pertama kali dialami oleh remaja disebut menarche. Normalnya menstruasi terjadi setiap 21 - 35 hari dan berlangsung selama lebih kurang 5 - 7 hari.

Remaja adalah individu yang rentan dan beresiko mengalami gangguan menstruasi. Hampir $75 \%$ remaja mengalami menstruasi diantaranya siklus yang tidak teratur, nyeri, perdarahan yang lama dan banyak saat menstruasi (Karout, Hawai, \& Altuwaijri, 2012). Penelitian serupa juga dilakukan di Malaysia dan hasilnya mayoritas remaja putri mengalami gangguan menstruasi seperti menstruasi yang tertunda, siklus menstruasi yang tidak teratur, nyeri dan perdarahan yang banyak saat menstruasi (Lee, Chen, Lee, \& Kaur, 2006). Penelitian yang dilakukan di SMK YPKK 1 Sleman dengan menggunakan 100 remaja putri sebagai subjek penelitian ditemukan 5 responden (7.1\%) mengalami hipomenorea, hiperminorea 11 responden $(15.7 \%)$, poliminorea 9 responden $(12.9 \%)$, oligominorea 14 responden $(20.0 \%)$, aminorea 10 responden (14.3\%), disminorea 23 responden (32.9\%) Pre Mentrual Syndrome (PMS) yaitu sebanyak 25 responden (35.7\%) (Sahmin, 2017). 
Ketidakteraturan siklus menstruasi adalah kondisi umum pada wanita remaja. Pada hasil penelitian yang dilakukan di Australia, hampir 25\% manita memiliku gangguan menstruasi yang secara signifikan mempengaruhi kehidupan sehari-hari dan berdampak pada produktifitas di sekolah (Williams \& Creighton, 2012). Hasil studi biopsikososial menyebutkan bahwa siklus menstruasi tidak hanya dipengaruhi oleh faktor biologis saja seperti gaya hidup, gangguan hormonal, status gizi, bisa juga dipengaruhi oleh faktor sosial dan lingkungan. Hubungan dengan rekan kerja, keluarga, teman, sekolah serta faktor psikologis termasuk stress, depresi, kecemasan, faktor yang juga cukup berpengaruh (Mohamadirizi \& Kordi, 2013). Usia menarche juga berperan sebagai penentu ketidakteraturan siklus menstruasi diantaranya menarche dini dan keterlambatan usia menarche (Sianipar et al., 2009).

Status gizi dapat dijadikan sebagai tolak ukur kondisi tubuh seseorang yang dapat dilihat dari makanan apa saja yang dikonsumsi dan penggunaan zat-zat gizi di dalam tubuh (Almatsier, 2002). Indeks Massa Tubuh (IMT) dan kadar hemoglobin (Hb) dapat dijadikan indicator status gizi pada remaja. Ironisnya banyak remaja yang memiliki kebiasaan makan yang kurang baik sehingga berpengaruh terhadap siklus menstruasinya. Hampir 50\% remaja tidak sarapan setiap paginya dimana sarapan sangat penting untuk memenuhi kebutuhan nutrisi harian. Disisi lain remaja cenderung lebih menyukai makanan-makanan siap saji (junk food) daripada makanan sehat yang kaya nutrisi. Disisi lain, makanan siap saji tidak mengandung kandungan nutrisi yang cukup yang dapat memenuhi kebutuhuan tubuh (Adnyani,NKW., 2013).

Kekurangan maupun kelebihan gizi berpengaruh terhadap penurunan fungsi hipotalamus. Hipotalamus tidak dapat memberikan sinyal kepada hipofisa anterior untuk menghasilkan FSH (Follicle Stimulating Hormone) dan LH (Luteinizing Hormone). Dimana kedua hormone ini memiliki peran yang vital dalam siklus mentruasi. FSH berfungsi merangsang pertumbuhan folikel pada ovarium, Sedangkan LH berfungsi dalam pematangan sel telur. Jadi jika produksi FSH dan LH tergangu sudah pasti akan menggangu siklus menstruasi.

Melakukan aktivitas fisik yang teratur berpengaruh terhadap kebugaran fisik, kapasitas kerja dan kesehatan seseorang. Aktivitas fisik juga memiliki kaitan erat dengan masalah reproduksi pada wanita khususnya menstruasi. Aktivitas fisik teratur dapat meningkatkan kemampuan fisiologik organ tubuh hingga $25 \%$ dibandingkan dengan yang tidak melakukan 
aktivitas. Aktivitas fisik dapat meningkatkan produksi hormon estrogen yang sangat penting dalam proses menstruasi (Tambing, 2012)

Stress juga dapat mengganggu produksi hormone estrogen yang disebabkan oleh tingginya kadar hoirmon kortisol. Akibatnya, siklus menstruasi pun akan terganggu. Hasil penelitian menyebutkan bahwa, remaja putri dengan tingkat stress dari sedang hingga berat dan 59,2\% remaja di Pondok Pesantren Kuno Putri mengalami ketidakteraturan siklus menstruasi (Luthfa, 2017).

Usia menarche yang terlambat berhubungan dengan gangguan siklus menstruasi (Aziem, Ali, Rayis, Mamoun, \& Adam, 2011). Rata-rata usia menarche di Indonesia adalah 13 tahun (20,0\%). Sebagian besar terlambatnya menarche bisa bersifat sementara yang merupakan gejala dari aksis hipotalamus-hipofisisovarium yang belum matang (Badan Penelitian dan Pengembangan Kesehatan Kementerian Kesehatan RI, 2013). Berdasarkan latar belakang tersebut penulis ingin melakukan penelitian mengenai faktor-faktor yang memengaruhi keteraturan siklus haid remaja putri di SMA Negeri 2 Singaraja. Adapun tujuan dari penelitian ini adalah untuk mengetahui dan menganalisa faktor-faktor yang memengaruhi keteraturan siklus haid remaja putri di SMA Negeri 2 Singaraja.

\section{METODE PENELITIAN}

Penelitian ini merupakan penelitian analitik korelasional yaitu penelitian dilaksanakan untuk menganalisis hubungan antara IMT, kadar hemoglobin, aktivitas fisik, tingkat stress dan usia menarche terhadap keteraturan siklus haid, dengan rancangan penelitian potong lintang yaitu pengumpulan dan penilaian data IMT, kadar hemoglobin, aktivitas fisik, tingkat stress dan usia menarche terhadap keteraturan siklus haid dilakukan dalam satu waktu. Penelitian dilakukan dilakukan di SMA Negeri 2 Singaraja pada periode bulan Januari-Maret 2019. Sebanyak 65 orang remaja putri menjadi responden dalam penelitian ini, yang ditentukan dengan menggunakan teknik Probability Sampling dengan teknik pengambilan sampel yaitu simple random sampling dimana peneliti mengambil sampel berdasarkan daftar absen anak secara acak dengan metode proportionate stratified random sampling. Data dikumpulkan dengan menggunakan kuesioner, alat ukur seperti: timbangan, meteran, dan HB meter. Data dianalisis dengan menggunakan uji univariat dan bivariat korelasional. 


\section{HASIL}

Berdasarkan hasil penelitian didapatkan hasil sebagai berikut:

Tabel 1.Karakteristik Responden

\begin{tabular}{|c|c|c|c|}
\hline No & Variabel & Frekuensi (n) & Persentase (\%) \\
\hline \multirow[t]{3}{*}{1} & Umur & & \\
\hline & 17 tahun & 26 & 40 \\
\hline & 18 tahun & 39 & 60 \\
\hline \multirow[t]{5}{*}{2} & Indeks Masa Tubuh (kg/m²) & & \\
\hline & Berat Badan Kurang $(<18,5)$ & 20 & 30.8 \\
\hline & Berat Badan Normal $(18,5-22,9)$ & 33 & 50,8 \\
\hline & Berat Badan Berlebih $(23-29,9)$ & 10 & 15,4 \\
\hline & Obesitas $(>30)$ & 2 & 3,1 \\
\hline \multirow[t]{3}{*}{3} & Kadar Hemoglobin (g/dL) & & \\
\hline & Rendah $(<12)$ & 34 & 52,3 \\
\hline & Normal (12-16) & 31 & 47,7 \\
\hline \multirow[t]{5}{*}{4} & Aktivitas Fisik & & \\
\hline & Tidak Pernah & 15 & 23,1 \\
\hline & Ringan (1-2x/seminggu) & 33 & 50,8 \\
\hline & Sedang (2-3x/seminggu) & 10 & 15,4 \\
\hline & Tinggi (>3x seminggu) & 7 & 10,8 \\
\hline \multirow[t]{6}{*}{5} & Tingkat Stress & & \\
\hline & Tidak ada kecemasan $(<14)$ & 19 & 29,2 \\
\hline & Kecemasan ringan (14-20) & 17 & 26,2 \\
\hline & Kecemasan Sedang (21-27) & 29 & 44,6 \\
\hline & Kecemasan Berat (28-41) & 0 & 0 \\
\hline & Kecemasan Berat Sekali (42-56) & 0 & 0 \\
\hline \multirow[t]{7}{*}{6} & Usia Menarche & & \\
\hline & 10 tahun & 3 & 4,6 \\
\hline & 11 tahun & 9 & 13,8 \\
\hline & 12 tahun & 19 & 29,2 \\
\hline & 13 tahun & 24 & 36,9 \\
\hline & 14 tahun & 8 & 12,3 \\
\hline & 15 tahun & 2 & 3,1 \\
\hline \multirow[t]{3}{*}{7} & Keteraturan Siklus Haid & & \\
\hline & Teratur & 51 & 78,5 \\
\hline & Tidak Teratur & 14 & 21,5 \\
\hline
\end{tabular}

Sumber: Data Primer 2019

Berdasarkan Tabel 1 dapat disimpulkan bahwa dari segi usia, mayoritas responden (60\%) berusia 18 tahun, sedangkan sisanya berusia 17 tahun. Data indeks masa tubuh siswa juga sangat bervariasi. Separuh responden 50,8\% memiliki indeks masa tubuh yang normal atau dengan kata lain memiliki berat badan yang ideal, namun masih ada responden sebanyak 15,4 persen yang memiliki berat badan berlebih bahkan ada 2 orang yang mengalami obesitas. Selain IMT, status gizi responden juga dapat dilihat dari segi kadar hemoglobin. Dalam 
penelitian ini, perbandingan antara yang memiliki $\mathrm{Hb}$ normal dan anemia, hampir sebanding yaitu sebesar $52,3 \%$ dan $47,7 \%$ secara berturut turut.

Dari segi aktivitas fisik, sebagian responden 50,8\% melakukan aktivitas fisik dalam derajat ringan, sedangkan dari tingkat stress, hampir sebagian responden (44,6\%) mengalami kecemasan sedang. Rata-rata responden mengalami menarche pada usia 13 tahun. Sebanyak 51 orang responden $(78,5 \%)$ memiliki siklus haid yang teratur.

Tabel 2. Rerata Indeks Massa Tubuh, Usia, Usia Menarche dan Kadar Hemoglogin Responden

\begin{tabular}{clccc}
\hline No & \multicolumn{1}{c}{ Variabel } & Rerata \pm SD & Min & Max \\
\hline 1 & Umur (Tahun) & $17,60 \pm 0,49$ & 17 & 18 \\
2 & Indeks Masa Tubuh $\left(\mathrm{kg} / \mathrm{m}^{2}\right)$ & $20,58 \pm 3,49$ & 15,41 & 32,37 \\
3 & Kadar Hemoglobin $(\mathrm{g} / \mathrm{dL})$ & $11,73 \pm 2,08$ & 6,70 & 15,90 \\
4 & Usia Menarche (Tahun) & $12,47 \pm 1,11$ & 10 & 15 \\
\hline
\end{tabular}

Sumber: Data Primer 2019

Berdasarkan Tabel 2 maka dapat disimpulkan bahwa rerata umur responden adalah 17,60 $\pm 0,49$ tahun dengan nilai minimum 17 tahun dan maksimum 18 tahun. Rerata indeks masa tubuh adalah $20,58 \pm 3,49 \mathrm{~kg} / \mathrm{m}^{2}$ dan rerata kadar hemoglobin adalah 11,73 $\pm 2,08 \mathrm{~g} / \mathrm{dL}$. Rerata usia menarche adalah $12,47 \pm 1,11$ tahun.

Tabel 3. Pengaruh Indeks Masa Tubuh terhadap Keteraturan Siklus Haid

\begin{tabular}{lccccc}
\hline \multirow{2}{*}{ Indeks Massa Tubuh (IMT) } & \multicolumn{4}{c}{ Keteraturan Siklus haid } & \multirow{2}{*}{$\mathrm{p}$} \\
\cline { 2 - 5 } & $\mathrm{n}$ & $\%$ & $\mathrm{n}$ & $\%$ & \\
\cline { 2 - 5 } & 13 & 65 & 7 & 35 & \\
\hline Berat Badan Kurang $(<18,5)$ & 28 & 84,8 & 5 & 15,2 & 0,219 \\
Berat Badan Normal $(18,5-22,9)$ & 7 & 70 & 3 & 30 & \\
Berat Badan Berlebih $(23-29,9)$ & 1 & 50 & 1 & 50 \\
Obesitas $(>30)$ & & & & &
\end{tabular}

Sumber: Data Primer 2019

Berdasarkan tabel diatas maka dapat disimpulkan bahwa tidak ditemukan adanya korelasi antara IMT dengan keteraturan siklus haid $(\mathrm{p}=0,219 ; \mathrm{r}=-0,155)$

Tabel 4. Pengaruh Kadar Hemoglobin terhadap Keteraturan Siklus Haid

\begin{tabular}{|c|c|c|c|c|c|}
\hline \multirow{3}{*}{$\begin{array}{c}\text { Kadar Hemoglobin } \\
(\mathrm{g} / \mathrm{dL})\end{array}$} & \multicolumn{4}{|c|}{ Keteraturan Siklus haid } & \multirow[t]{3}{*}{$\mathbf{p}$} \\
\hline & \multicolumn{2}{|c|}{ Teratur } & \multicolumn{2}{|c|}{ Tidak Teratur } & \\
\hline & $\mathbf{n}$ & $\%$ & $\mathbf{n}$ & $\%$ & \\
\hline Rendah $(<12)$ & 22 & 64,7 & 12 & 35,3 & \\
\hline Normal (>12) & 27 & 87,10 & 4 & 12,90 & 0,007 \\
\hline
\end{tabular}

Sumber: Data Primer 2019 
Berdasarkan tabel 4 dapat disimpulkan bahwa ada pengaruh kadar hemoglobin terhadap keteraturan siklus haid dengan nilai $\mathrm{p}=0,005$ dan nilai $\mathrm{r}=-0,330$.

Tabel 5. Pengaruh Tingkat Aktivitas Fisik terhadap Keteraturan Siklus Haid

\begin{tabular}{|c|c|c|c|c|c|}
\hline \multirow[t]{3}{*}{ Aktivitas Fisik } & \multicolumn{4}{|c|}{ Keteraturan Siklus haid } & \multirow[t]{3}{*}{$\mathbf{p}$} \\
\hline & \multicolumn{2}{|c|}{ Teratur } & \multicolumn{2}{|c|}{ Tidak Teratur } & \\
\hline & $\mathbf{n}$ & $\%$ & $\mathbf{n}$ & $\%$ & \\
\hline Tidak Pernah & 9 & 60 & 6 & 40 & 0,047 \\
\hline Ringan (1-2x/seminggu) & 27 & 81,82 & 6 & 18,18 & \\
\hline Sedang $(2-3 x /$ seminggu $)$ & 8 & 80 & 2 & 20 & \\
\hline Tinggi (>3x seminggu) & 7 & 100 & 0 & 0 & \\
\hline
\end{tabular}

Sumber: Data Primer 2019

Berdasarkan Tabel 5 dapat disimpulkan bahwa ada pengaruh tingkat aktivitas fisik terhadap keteraturan siklus haid dengan nilai $p=0,047$ dan nilai $r=-0,232$

Tabel 6. Pengaruh Tingkat Stress terhadap Keteraturan Siklus Haid

\begin{tabular}{|c|c|c|c|c|c|}
\hline \multirow[t]{3}{*}{ Tingkat Stress } & \multicolumn{4}{|c|}{ Keteraturan Siklus haid } & \multirow[t]{3}{*}{$\mathbf{p}$} \\
\hline & \multicolumn{2}{|c|}{ Teratur } & \multicolumn{2}{|c|}{ Tidak Teratur } & \\
\hline & $\mathbf{n}$ & $\%$ & $\mathbf{n}$ & $\%$ & \\
\hline Tidak ada kecemasan $(<14)$ & 18 & 94,73 & 1 & 5,27 & \\
\hline Kecemasan ringan $(14-20)$ & 15 & 88,23 & 2 & 11,77 & 0,005 \\
\hline Kecemasan Sedang (21-27) & 18 & 62,06 & 11 & 37,94 & \\
\hline Kecemasan Berat (28-41) & 0 & 0 & 0 & 0 & \\
\hline Kecemasan & 0 & 0 & 0 & 0 & \\
\hline Berat Sekali (42-56) & & & & & \\
\hline
\end{tabular}

Sumber: Data Primer 2019

Berdasarkan Tabel 4.5 dapat disimpulkan bahwa ada pengaruh tingkat stress terhadap keteraturan siklus haid dengan nilai $\mathrm{p}=0,005$ dan nilai $\mathrm{r}=0,334$

Tabel 7. Pengaruh Usia menarche terhadap Keteraturan Siklus Haid

\begin{tabular}{|c|c|c|c|c|c|}
\hline \multirow[t]{3}{*}{ Usia Menarche } & \multicolumn{4}{|c|}{ Keteraturan Siklus haid } & \multirow[t]{3}{*}{$\mathbf{p}$} \\
\hline & \multicolumn{2}{|c|}{ Teratur } & \multicolumn{2}{|c|}{ Tidak Teratur } & \\
\hline & $\mathbf{n}$ & $\%$ & $\mathbf{n}$ & $\%$ & \\
\hline 10 tahun & 1 & 33,33 & 2 & 66,67 & \\
\hline 11 tahun & 7 & 77,77 & 2 & 22,23 & 0,696 \\
\hline 12 tahun & 16 & 84,21 & 3 & 15,79 & \\
\hline 13 tahun & 20 & 83,33 & 4 & 16,67 & \\
\hline 14 tahun & 5 & 62,5 & 3 & 37,5 & \\
\hline 15 tahun & 2 & 100 & 0 & 0 & \\
\hline
\end{tabular}


Berdasarkan tabel 7 dapat disimpulkan bahwa tidak ada korelasi antara usia menarche dengan keteraturan siklus haid dengan nilai $\mathrm{p}=0,696$ dan nilai $\mathrm{r}=-0,044$

\section{PEMBAHASAN}

\section{Status Gizi}

Berdasarkan hasil penelItian ini, tidak ditemukan adanya korelasi antara IMT dengan keteraturan siklus haid. Hal ini sangat bertolak belakang dengan teori yang mengatakan bahwa kadar IMT berhubungan dengan adanya lemak di dalam tubuh. Lemak dalam tubuh mempengaruhi kadar hormon insulin dan leptin. Kedua hormone tersebut mempengaruhi sekresi GnRH (Gonadotropin Releasing Hormone). Sekresi GnRH merangsang pengeluaran FSH (Folicle Stimulating Hormone) dan LH (Luteinizing Hormone) yang berperan untuk merangsang ovarium untuk melakukan folikulogenesis dan steroidogenesis (menghasilkan estrogen dan progesteron). Kelainan hipotalamus atau pituitari, kadar estrogen yang tidak normal, serta kelainan pada ovarium dapat menyebabkan gangguan menstruasi (Zalni, Harahap, \& Desfita, 2017).

Kadar lemak yang tinggi dalam tubuh wanita khususnya remaja akan mempengaruhi produksi hormon estrogen. Seperti yang kita ketahui estrogen tidak hanya dihasilkan oleh ovarium, melainkan dihasilkan pula oleh jaringan adiposa. Akibatnya, kadar estrogen akan meningkat pada individu yang memiliki kadar lemak tubuh tinggi. Produksi dan kadar hormon yang tidak seimbang inilah yang dapat memicu terjadinya gangguan menstruasi (Karina, Candra, \& Soedarto, 2017).

Bertolak belakang denga apa yang dijelaskan sebelumnya, ada penelitian yang menyatakan bahwa gangguan menstruasi termasuk ketidakteraturan siklus haid dapat terjadi pada semua kategori IMT (kurang, normal, berlebih, obesitas). Penyebab lain yang diduga menyebabkan bertolak belakangnya hasil yang didapat bahwa dari seluruh responden hanya 2 orang responden yang mengalami obesitas, sehingga dianggap kurang representative untuk mewakili golongan obesitas (Astuti \& Noranita, 2016).

Disisi lain, indikator status gizi lainnya yaitu kadar hemoglobin ditemukan memiliki korelasi yang kuat terhadap keteraturan siklus haid. Siklus menstruasi yang tidak normal bisa disebabkan karena seorang wanita mengalami anemia. Anemia dan kadar hemoglobin dalam tubuh sangat mempengaruhi ketarutan siklus menstruasi. Kurangnya kadar hemoglobin dalam tubuh menyebabkan suplay oksigen keseluruh tubuh menjadi berkurang. Akibatnya, produksi 
hormone Folikel Stimulating hormone (FSH) dan Luteinizing Hormone (LH) yang di hasilkan oleh hipotalamus menjadi berkurang.

\section{Aktivitas Fisik}

Berdasarkan hasil penelitian ditemukan bahwa ada korelasi antara aktivitas fisik dengan keteraturan siklus haid walaupun dengan kekuatan korelasi yang lemah. Aktivitas fisik secara tidak langsung berperan penting dalam pencegahan berbagai penyakit. Aktivitas fisik minimal maupun aktivitas fisik berlebih dapat berpengaruh negatif terhadap kesehatan reproduksi. Terutama pada negara berkembang dimana masyarakatnya lebih banyak mengabiskan energi untuk bekerja dan transporttasi dibandingkan untuk berolahraga (MacNiven, Bauman, \& Abouzeid, 2012). Olahraga atau aktivitas fisik yang teratur dapat mencegah terjadinya gangguan kesehatan dismenorrhea, mencegah obesitas, mengurangi risiko kanker payudara (Wojtyła, Kapka-Skrzypczak, Biliński, \& Paprzycki, 2011). Aktivitas fisik berlebihan menyebabkan disfungsi hipotalamus yang menyebabkan gangguan sekresi GnRH sehingga menurunkan kadar hormone estrogen (Ganong, 2008).

\section{Tingkat Stress}

Disaat tubuh mengalami tekanan atau beban yang menyebabkan keseimbangan badan dan jiwa yang terganggu, maka tubuh akan memberikan respon nonspesifik dan berusaha untuk mengembalikan dalam bentuk stres. Implikasi stress dapat berupa stres yang tidak menyenangkan dan menyenangkan dan dibutuhkan penyesuaian untuk menerima kondisi tersebut. Jadi usaha untuk beradaptasi dan penyesuaian diri disebut dengan stress (Willy F \& Albert A, 2009).

Dalam penelitian ini ditemukan adanya korelasi yang sangat kuat antara tingkat stress dengan keteraturan siklus haid. Pada kondisi stres terjadi pengaktifan aksis HPA, sehingga Corticotropic Releasing Hormone (CRH) disekresikan oleh hipotalamus. CRH berperan menghambat sekresi GnRH sehingga berpengaruh terhadap penurunan fungsi reproduksi wanita (Breen \& Karsch, 2004). CRH menstimulasi pelepasan Adenocorticotropin Hormon (ACTH) oleh hipofisis anterior. ACTH menstimulasi kelenjar adrenal untuk menghasilkan hormon kortisol. Hormon kortisol inilah yang menghambat sekresi LH berperan dalam menghambat sekresi LH dengan cara menghambat respon hipofisis anterior terhadap GnRH (Hall, 2007).

Hormon LH berperan penting dalam siklus menstruasi. LH berperan dalam proses folikulogenesis dan produksi hormone steroid seperti estrogen dan progesterone. Hormon estrogen dan progesteron memiliki peranan dalam mengatur siklus menstruasi setiap 
bulannya. Keseimbangan hormone estrogen dan progesterone ini sangat dipengaruhi oleh hormone kortisol. Tingginya produksi kortisol dalam tubuh menggangu keseimbangan hormone estrogen dan progesterone sehingga siklus menstruasi menjadi tidak teratur (Pratiwi, 2017).

\section{Usia Menarche}

Segera setelah menarche, respon umpan balik positif terhadap estrogen yang memicu terjadinya ovulasi sering tidak terjadi. Aksis hipotalamus-pituitari dan ovarium (HPO) belum matang secara sempurna sampai 5 tahun setelah menarche, dan siklus anovulasi umum ditemui pada remaja (hampir 50\% siklus bersifat anovulasi pada satu tahun pertama. Saat aksis HPO sudah matang, siklus mentruasi dan ovulasi akan menjadi teratur, umunya dua tahun setelah mengalami menarche (De Sanctis et al., 2019)

Pada penelitian ini tidak ditemukan adanya korelasi antara usia menarche dengan keteraturan siklus haid. Hal ini disebabkan karena mayoritas usia menarche responden adalah diusia 13 tahun, sedangkan pada saat pengumpulan data, responden berusia 17-18 tahun. Hal ini menandakan bahwa mayoritas responden sudah mengalami siklus ovulatoir dikarenakan aksis HPO yang sudah semakin matang diusianya. Dengan kata lain, hormon-hormon reproduksi sudah terbentuk sempurna sehingga siklus menstruasi menjadi teratur dibandingkan dengan saat menarche.

Hal ini sejalan dengan penelitian oleh (Pratiwi, 2017) yang menyatakan bahwa tidak terdapat hubungan antara usia saat menarche dengan pola siklus menstruasi. Menarche biasanya terjadi diusia 12-13 tahun. Jadi semakin dini usia menarche, semakin cepat terjadi siklus menstruasi yang teratur, begitu pula sebaliknya. (Aryani, Rachma, Rokhayati, \& Moelyo, 2018) menyebutkan bahwa pada remaja Indonesia ketidakteraturan siklus menstruasi merupakan hal yang wajar pada 5 tahun pertama setelag menarche. Fungsi ovarium akan semakin matang dimulai pada satu tahun pertama setelah menarche.

\section{KESIMPULAN}

Berdasarkan hasil penelitian dan Analisa data maka dapat disimpulkan bahwa ada hubungan/pengaruh antara kadar $\mathrm{Hb}$, aktivitas fisik dan tingkat stress terhadap keteraturan siklus menstruasi. Tidak ada hubungan antara IMT dan usia menarche dengan keteraturan siklus menstruasi pada remaja putri. Diharapkan remaja rutin meminum suplemen penambah darah sebagai bentuk pencegahan terhadap anemia dan menjalankan pola hidup sehat diantaranya rutin berolahraga, makan-makanan yang sehat, dan meminimalisir stress. 


\section{UCAPAN TERIMA KASIH}

Penelitian mengucapkan terima kasih kepada Institut Teknologi dan Kesehatan Bali selaku pemberi dana penelitian, SMA Negeri 2 Singaraja sebagai lokasi penelitian serta seluruh responden dalam penelitian ini.

\section{DAFTAR PUSTAKA}

Adnyani,NKW., N. N. G. (2013). Hubungan Status Gizi Dengan Siklus Menstruasi Pada Remaja Putri Kelas X Putri Kelas X di SMA PGRI 4 DENPASAR. Journal of Chemical Information and Modeling, 53(9), 1689-1699.

Almatsier, S. (2002). Prinsip dasar ilmu gizi. Jakarta: Gramedia Pustaka Utama. Retrieved from

https://books.google.co.id/books/about/Prinsip_dasar_ilmu_gizi.html?id=aEmYNwAAC AAJ\&hl=id

Aryani, I., Rachma, U. P., Rokhayati, E., \& Moelyo, A. G. (2018). Menstrual cycle patterns of Indonesian adolescents. Paediatrica Indonesiana, 58(3), 101-105. https://doi.org/10.14238/pi58.3.2018.101-5

Astuti, E. P., \& Noranita, L. (2016). Prevalensi kejadian gangguan menstruasi berdasarkan indeks masa tubuh (imt) pada siswa kelas VII smp. Jurnal Ilmu Kebidanan, 3(1), 58-64. Retrieved from http://jurnal.akbiduk.ac.id/assets/doc/170116020106-9 PREVALENSI KEJADIAN MENSTRUASI.pdf

Aziem, A., Ali, A., Rayis, D. A., Mamoun, M., \& Adam, I. (2011). Age at menarche and menstrual cycle pattern among schoolgirls in Kassala in eastern Sudan. Journal of Public Health and Epidemiology, 3(3), 111-114. Retrieved from http://www.academicjournals.org/jphe

Badan Penelitian dan Pengembangan Kesehatan Kementerian Kesehatan RI. (2013). RISET KESEHATAN DASAR. Jakarta: Kementerian Kesehatan RI.

Breen, K. M., \& Karsch, F. J. (2004). Does Cortisol Inhibit Pulsatile Luteinizing Hormone Secretion at the Hypothalamic or Pituitary Level? Endocrinology, 145(2), 692-698. https://doi.org/10.1210/en.2003-1114

De Sanctis, V., Rigon, F., Bernasconi, S., Bianchin, L., Bona, G., Bozzola, M., ... Perissinotto, E. (2019). Age at Menarche and Menstrual Abnormalities in Adolescence: Does it Matter? The Evidence from a Large Survey among Italian Secondary Schoolgirls. Indian Journal of Pediatrics, 86, 34-41. https://doi.org/10.1007/s12098018-2822-x

Felicia, F., Hutagaol, E., \& Kundre, R. (2015). Hubungan Status Gizi Dengan Siklus Menstruasi Pada Remaja Putri Di Psik Fk Unsrat Manado. Jurnal Keperawatan UNSRAT, 3(1), 110354.

Ganong, W. F. (2008). Buku Ajar Fisiologi Kedokteran Edisi 22 (22nd ed.). Jakarta: EGC. Hall, J. (2007). Guyton and Hall Textbook of Medical Physiology (11th ed.). Elsevier.

Karina, E. S., Candra, A., \& Soedarto, J. H. (2017). Hubungan Obesitas Sentral Dengan Siklus Menstruasi Dan Dysmenorrhea Primer Pada Remaja. Journal of Nutrition 
College, 6(4), 319-325. $\quad$ Retrieved from https://media.neliti.com/media/publications/200466-hubungan-obesitas-sentral-dengansiklus.pdf

Karout, N., Hawai, S. M., \& Altuwaijri, S. (2012). Prevalence and pattern of menstrual disorders among Lebanese nursing students. Eastern Mediterranean Health Journal, 18(4), 346-352. https://doi.org/10.26719/2012.18.4.346

Lee, L. K., Chen, P. C. Y., Lee, K. K., \& Kaur, J. (2006). Menstruation among adolescent girls in Malaysia: A cross-sectional school survey. Singapore Medical Journal, 47(10), 869-874.

Luthfa, A. (2017). GAMBARAN SIKLUS MENSTRUASI PADA REMAJA PUTRI DILIHAT BERDASARKAN TINGKAT STRESS DI PONDOK PESANTREN KUNO PUTRI GAMPING SLEMAN. SEKOLAH TINGGI ILMU KESEHATANJENDERAL ACHMAD YANI.

MacNiven, R., Bauman, A., \& Abouzeid, M. (2012). A review of population-based prevalence studies of physical activity in adults in the Asia-Pacific region. BMC Public Health, 12(1), 41. https://doi.org/10.1186/1471-2458-12-41

Mohamadirizi, S., \& Kordi, M. (2013). Association between menstruation signs and anxiety, depression, and stress in school girls in Mashhad in 2011-2012. Iranian Journal of Nursing and Midwifery Research, 18(5), 402-407. Retrieved from http://www.ncbi.nlm.nih.gov/pubmed/24403944\%0Ahttp://www.pubmedcentral.nih.gov/ articlerender.fcgi?artid=PMC3877464

Parveen, A., \& Siddiqui, M. J. (2012). Evaluation of Knowledge of Perception And Coping Strategies of Perimenopausal Women Through Self Inustructional Module (SIM). Evaluation of Knowledge of Perception And Coping Strategies of Perimenopausal Women Through Self Inustructional Module (SIM), 1(7), 42-45.

Pratiwi, A. Z. (2017). HUBUNGAN ANTARA USIA MENARCHE DENGAN LAMA SIKLUS MENSTRUASI DAN KEJADIAN DISMENORE PRIMER PADA REMAJA PUTRI DI SMA NEGERI 1 MAKASSAR. Universitas Hasanuddin.

Prawirohardjo, S. (2014). Ilmu Kandungan (3rd ed.). Jakarta: PT.Bina Pustaka.

Sahmin. (2017). Prevalensi gangguan menstruasi pada remaja putri di SMK YPKK 1 Sleman. STIKES Jenderal Achmad Yani.

Sianipar, O., Bunawan, N. C., Almazini, P., Calista, N., Wulandari, P., Rovenska, N., ... Suarthana, E. (2009). Prevalensi Gangguan Menstruasi dan Faktor-Faktor yang Berhubungan pada Siswi SMU di Kecamatan Pulo Gadung Jakarta Timur. Maj Kedokt Indon, 59(7), 308-313. Retrieved from http://www.academia.edu/download/44385535/653-707-1-PB.pdf

Tambing, Y. (2012). AKTIVITAS FISIK DAN SINDROM PREMENSTRUASI PADA REMAJA. Universitas Gadjah Mada.

Tim Penulis Poltekkes Kemenkes Jakarta. (2010). Kesehatan Remaja: Problem dan Solusinya. Jakarta: Salemba Medika.

Williams, C. E., \& Creighton, S. M. (2012). Menstrual disorders in adolescents: Review of current practice. Hormone Research in Paediatrics, 78(3), 135-143. https://doi.org/10.1159/000342822 
Willy F, M., \& Albert A, M. (2009). Catatan ilmu kedokteran jiwa (2nd ed.). Surabaya2: Airlangga University Press.

Wojtyła, A., Kapka-Skrzypczak, L., Biliński, P., \& Paprzycki, P. (2011). Physical activity among women at reproductive age and during pregnancy (Youth Behavioural Polish Survey - YBPS and pregnancy-related assessment monitoring survay - PrAMS) epidemiological population studies in Poland during the period 2010-2011. Annals of Agricultural and Environmental Medicine, 18(2), 365-374.

Zalni, R., Harahap, H., \& Desfita, S. (2017). Usia Menarche Pada Anak Perempuan Berhubungan Dengan Status Gizi, Konsumsi Makanan Dan Aktivitas Fisik. Jurnal Kesehatan Reproduksi, 8(2), 153-161. https://doi.org/10.22435/kespro.v8i2.6918.153161 